\title{
Investigation on the corrosion inhibiting property of modified cashew nutshell liquid
}

\author{
O.M. Fayomi, ${ }^{1}{ }^{1}$ D.C. Ike, ${ }^{1}{ }^{10} *$ M.A. Iorhemba, ${ }^{1}$ O.M. Ameh, ${ }^{2}$ \\ N.E. Ihegwuagu ${ }^{3}$ and R.C. Kalu ${ }^{1}$ \\ ${ }^{1}$ Department of Chemistry, University of Agriculture Makurdi, P.M.B. 2373 Makurdi, \\ Benue State, Nigeria \\ ${ }^{2}$ Department of Applied Chemistry Federal University Dutsin-ma, P.M.B. 5001 Dutsin-ma \\ Katsina State, Nigeria \\ ${ }^{3}$ Department of plant Resources, Agricultural Research Council of Nigeria (ARCN) Abuja, \\ Nigeria \\ *E-mail: ike.david@uam.edu.ng
}

\begin{abstract}
The corrosion inhibiting property of modified cashew nutshell liquid (CNSL) in controlling corrosion of aluminium in $0.1 \mathrm{M} \mathrm{HCl}$ medium has been evaluated by gravimetry analysis. Gravimetry analysis was carried out at various inhibitor concentrations of 0.2, 0.4, 0.6, 0.8 and $1.0 \mathrm{~g} / \mathrm{L}$, at temperatures of $303,313,323$ and $333 \mathrm{~K}$ and time intervals of $24,48,72,96$ and $120 \mathrm{~h}$ respectively. The pseudo first and second order kinetic model was used to study the kinetic contribution. Four adsorption isotherms, viz., Langmuir, Temkin, Freundlich and El-Awady, were used to study the adsorption mechanism. Thermodynamic parameters were also investigated. Gravimetry analysis reveals that the inhibition efficiency increases as the inhibitor concentration increases but decreased with increasing temperature and immersion time. Data from the kinetic study carried out, showed a pseudo-second order. Adsorption isotherm studies revealed that the Freundlich isotherm model best describes the adsorption of the inhibitor to the aluminium surface, The Gibbs free energy change was evaluated from the adsorption isotherm and the values $(-10.14,-10.26,-10.49$ and $-10.80 \mathrm{~kJ} / \mathrm{mol})$ obtained were less than $-20 \mathrm{~kJ} / \mathrm{mol}$ indicating a physisorption mechanism and spontaneity. Values of activation energy obtained, $E_{\mathrm{a}}$ $(19.10,22.38,23.70,30.12,60.43$ and $48.44 \mathrm{~kJ} / \mathrm{mol})$, indicated that the physisorption mechanism operates, while the positive values of change in enthalpy of activation, $\Delta H$, indicated an endothermic process. The CNSL-triethanolamine ether derivative proved to be a great corrosion inhibitor for aluminium corrosion in acidic environment.
\end{abstract}

Received: August 12, 2021. Published: September 17, 2021

doi: $\underline{10.17675 / 2305-6894-2021-10-3-27}$

Keywords: corrosion, inhibition, cashew nutshell liquid, triethanolamine, kinetics, thermodynamic and adsorption isotherm. 


\section{Introduction}

There are various means of controlling, mitigating and prevention of corrosion and these include coating, cathode protection, material selection, and use of inhibitors. Great percentage of synthetic chemical inhibitors which have been used as corrosion inhibitors are toxic and environmentally unfriendly posing adverse effect on our ecosystem. This has thus stirred up the use of natural product as corrosion inhibitors [1].

Corrosion inhibitors are substances which when added in small concentrations and quantity to corrosive media decrease or prevent the deterioration of the metals the media [2]. Organic compounds that possess polar functional groups such as nitrogen, Sulphur and oxygen in their conjugated systems have been evaluated to be very efficient in corrosion inhibition for metals [3-5]. Owing to the biodegradability, non-toxic nature and the presence of phytochemical compounds such as alkaloids, tannins, flavonoids, saponins, amino acids, ascorbic acid, phenolic acids, pigments, resins and triterpenoids which contains various of polar functional groups (possess multiple active centres) and molecular electronic structures similar to convention synthetic corrosion inhibitors in plant, plant extracts are therefore seen and used as sources of non-toxic and inexpensive corrosion inhibitors [6].

Generally, the inhibition capacity of plants extract is ascribed to the adsorption of organic moieties of the plant extract on the metal surface thereby forming a protective barrier on metal surfaces $[7,8]$. The inhibition efficiency of the inhibitor is a comparative evaluation of by the energy released on creating the metal-inhibitor bond to the corresponding changes when the mineral acid reacts with the metal [9].

CNSL is a cheap and readily available renewable material found in the form of thick reddish-brown oil in the interior sponge part of the CNS from the cashew plant Anacardium occidentale [10]. Chemically, CNSL is composed of four major phenolic liquids, namely: anacardic acid, cardanol, cardol and traces of 2-methylcardol (Figure 1) in varying ratios owing to the extraction technique employed. The structural composition of the components of CNSL has resulted in its vast industrial applications [11]. This study focuses at investigating the inhibition efficiency of CNSL modified with TEA using epichlorohydrin as a linking agent. It also gives reports on the thermodynamic and kinetic components of the corrosion inhibition processes.

\section{Experimental Methods}

\subsection{Preparation of Specimens}

Aluminium specimen used in this work were obtained from a commercial vendor. The Aluminium specimen was mechanically press cut to coupons of dimension $3.1 \times 2.2 \mathrm{~cm}^{2}$ with surface area $6.82 \mathrm{~cm}^{2}$. 


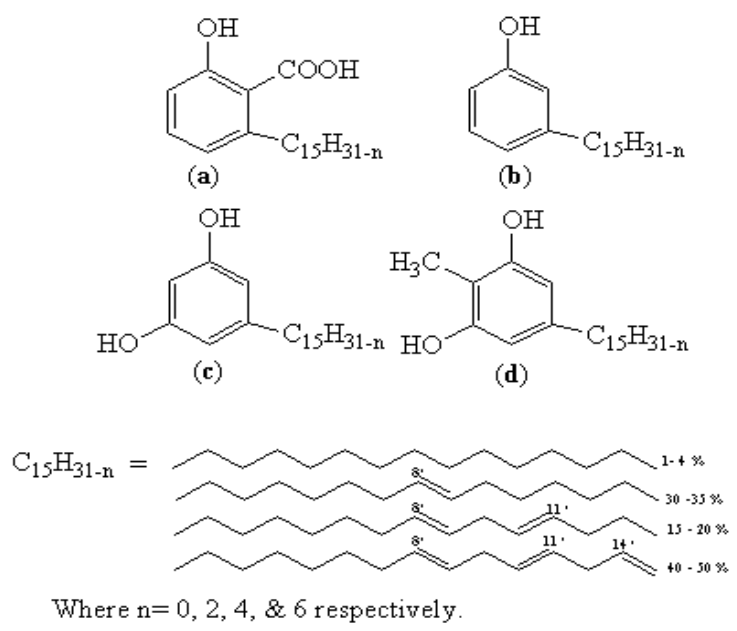

Figure 1. Chemical composition of CNSL: (a) anacardic acid, (b) cardanol, (c) cardol, (d) 2-methylcardol [11].

\subsection{Preparation of the Plant Extract}

CSN obtained from a commercial vendor was washed and dried in sunlight to remove contaminations. The washed shell was dekernelled and crushed to smaller sizes using mortar and pestle. The crushed shell (500 g) was wrapped in a filter paper and underwent extraction in $1000 \mathrm{~mL} n$-hexane by reflux in a Soxhlet extraction thimble and CNSL. The extracted oil was concentrated using a rotary evaporator.

\subsection{Synthesis of Organic Inhibitor}

The first step was the epoxidation of CNSL with epichlorohydrin. The reaction scheme was adapted from Atta et al., 2016 [12] and Suresh et al., 2005 [13], with a few modifications. CNSL $(0.17 \mathrm{~mol} ; 60.0 \mathrm{~mL}), \mathrm{NaOH}(0.34 \mathrm{~mol} ; 13.8 \mathrm{~g})$ and epichlorohydrin $(0.17 \mathrm{~mol}$; $13.77 \mathrm{~mL}$ ) were mixed together in $150 \mathrm{~mL}$ round bottom flask. The resulting solution was refluxed in a paraffin bath at $150^{\circ} \mathrm{C}$ for $3 \mathrm{~h}$, then TEA $(0.17 \mathrm{~mol} ; 22.60 \mathrm{~mL})$ was added and further refluxed for $3 \mathrm{~h}$ more at $150^{\circ} \mathrm{C}$. The reaction mixture was filtered and washed with $20 \mathrm{~mL}$ of $0.1 \mathrm{M} \mathrm{HCl} / \mathrm{excess}$ water to remove white crystalline residue of $\mathrm{NaCl}$. The oil was recovered by solvent extraction with ethyl acetate and filtered through $\mathrm{Na}_{2} \mathrm{SO}_{4}$ crystals to remove any water molecules. The oil was distilled to remove ethyl acetate under reduced pressure and dried in a desiccator for $24 \mathrm{~h}$ (Scheme 1).

\subsection{Weight Loss Measurements}

The Aluminum coupons were polished, weighed and suspended in the test solutions with and without the inhibitor at different temperatures of 303, 313,323 and $333 \mathrm{~K}$ and inhibitor concentrations of $0.2,0.4,0.6,0.8$ and $1.0 \mathrm{~g} / \mathrm{L}$ for $6 \mathrm{~h}$. Coupons were thereafter removed from the solutions, polished, dried and weighed on an electronic balance to the final reading. Similar process was subsequently repeated for $24,48,72,96,120$ and $144 \mathrm{~h}$. 


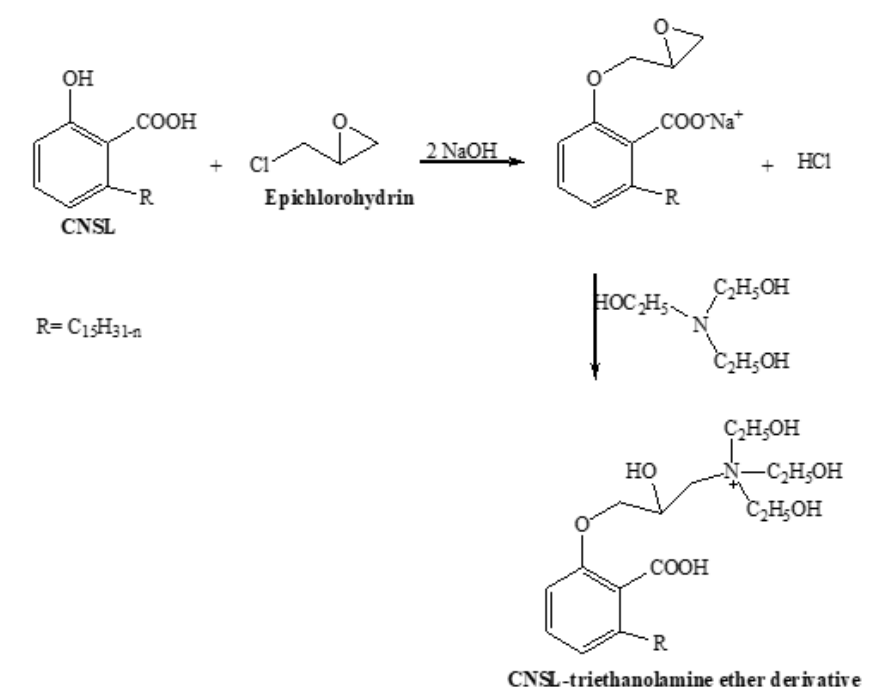

Scheme 1. Synthetic pathway for CNSL-Triethanolamine derivative.

\subsection{Determination of inhibition effect of Modified CNSL}

The corrosion inhibition efficacy of synthesized CNSL-Triethanolamine derivative on aluminium in $0.1 \mathrm{M} \mathrm{HCl}$ medium was evaluated by determining the inhibition efficiency, surface coverage and corrosion rate from the weight loss measurement using equations (1), (2) and (3) as reported by Abeng et al. [6] and Ijuo et al. [1]:

$$
\begin{gathered}
\% I E=1-\frac{C_{\mathrm{R}_{\text {inh }}}}{C_{\mathrm{R}_{\text {Blank }}}} \cdot 100 \\
\theta=\frac{I E}{100} \\
C_{R}\left(\mathrm{~g} \mathrm{~h}^{-1} \mathrm{~cm}^{-2}\right)=\frac{W_{\text {loss }}}{A t}
\end{gathered}
$$

\subsection{Determination of adsorption isotherms and constants}

The study of adsorption isotherm reveals the mechanism of adsorption of CNSLTriethanolamine derivative to the aluminium surface [14]. Four isotherms, namely: Langmuir, Temkin, Freundlich and El-Awady, were tested using equation (4), (5), (6) and (7), respectively [15-17].

$$
\begin{gathered}
\frac{C}{\theta}=\frac{1}{K_{\mathrm{ads}}}+C \\
\theta=\ln C+K_{\mathrm{ads}} \\
\log \theta=\log K+n \log C
\end{gathered}
$$




$$
\begin{gathered}
\log \left(\frac{\theta}{1-\theta}\right)=y \log C+\log K \\
K_{\mathrm{ads}}=K^{1 / y}
\end{gathered}
$$

\section{Results and Discussion}

\subsection{Effect of temperature change}

The influence of temperature on the corrosion inhibition capacity of the modified CNSL was evaluated at various temperatures - 303, 313, 323 and $333 \mathrm{~K}$ considering the weight loss measurements, corrosion rate values and inhibition efficiencies obtained for various concentrations of the inhibitor investigated (Table 1). Correlation of these values with temperature changes showed the following:

a) Weight loss increased with increasing temperature and decreased with increasing concentration of inhibitors (Figure 1).

b) Corrosion rate increased with increasing temperature and decreased with increasing concentration of inhibitors (Figure 2)

c) Inhibition efficiency decreased with increasing temperature and increased with increasing concentration of inhibitor (Figure 3).

These observations are proving that the synthesized inhibitor is an effective corrosion inhibitor for aluminium in acidic environment $(\mathrm{HCl})$. The reduction of inhibition efficacy with increasing temperature can be ascribed to the nature of the adsorption of the inhibitor on the metal surface. In this case physisorption was favoured [18].

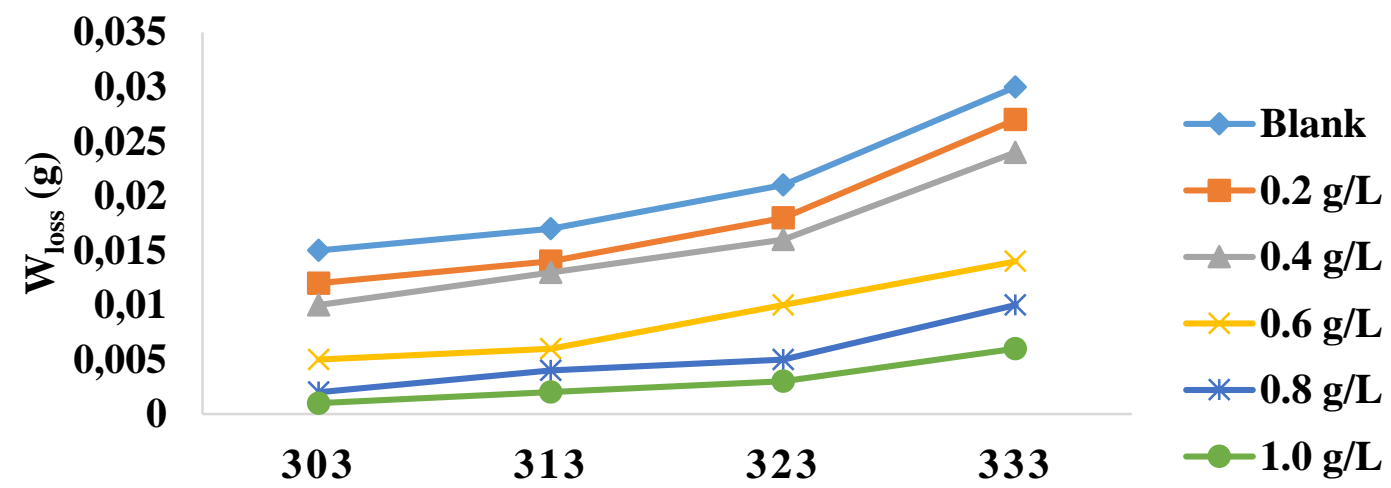

Temperature (K)

Figure 1. Effect of temperature changes on weight loss. 


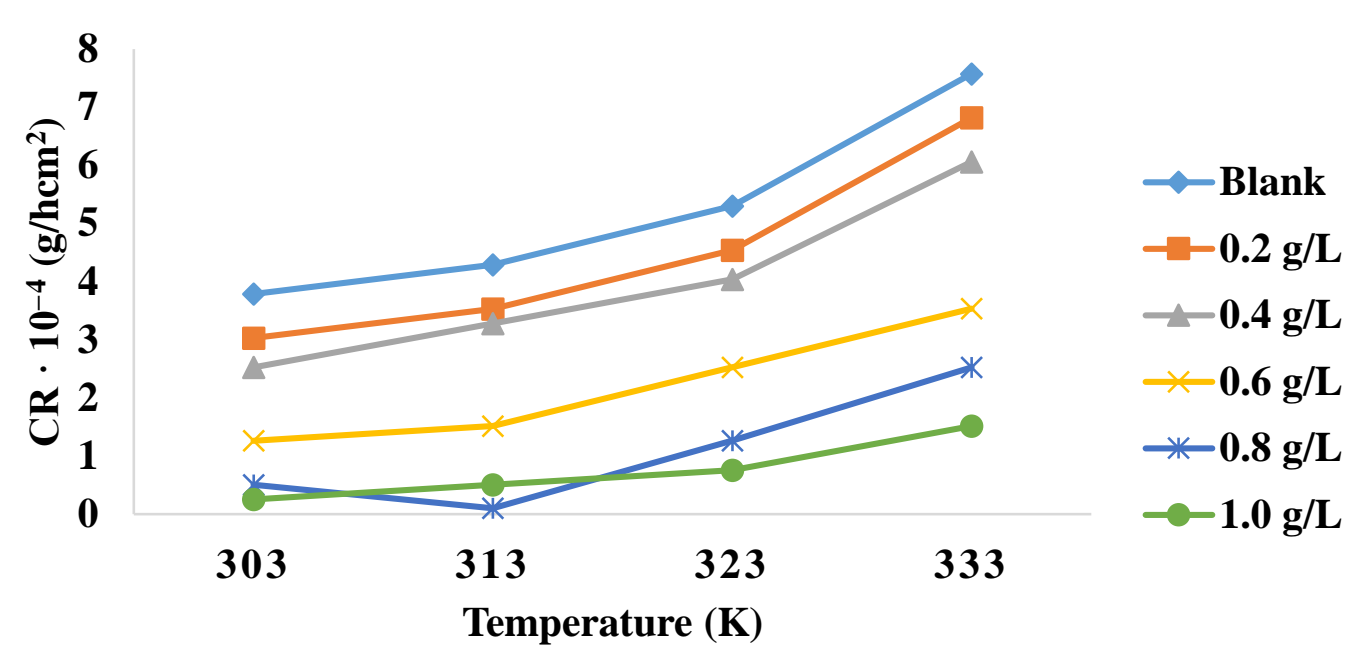

Figure 2. Effect of temperature change on corrosion rate.

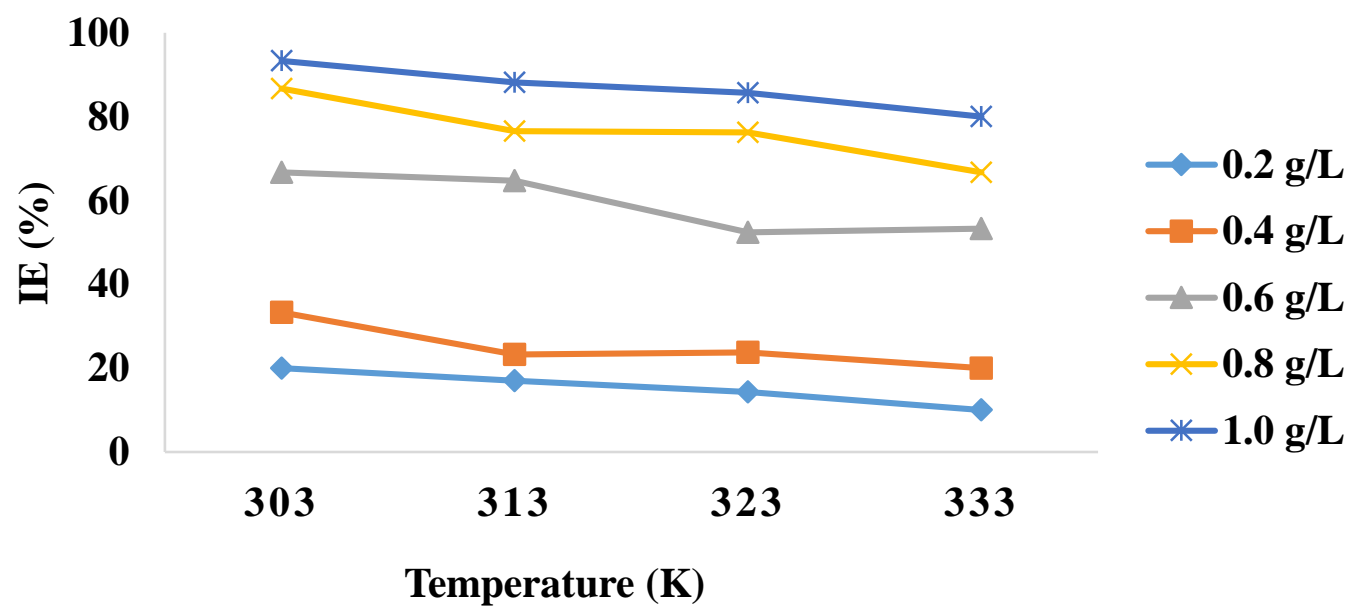

Figure 3. Effect of temperature change on inhibition efficiency.

Table 1. Effect of temperature changes on weight loss, corrosion rate and inhibition efficiency of the modified CNSL.

\begin{tabular}{cccc}
\hline Conc. $(\mathbf{g} / \mathbf{L})$ & $W_{\text {loss }}(\mathbf{g})$ & $\boldsymbol{C R} \cdot \mathbf{1 0}^{-\mathbf{4}}\left(\mathbf{g} / \mathbf{h c m}^{\mathbf{2}}\right)$ & $\boldsymbol{I E}(\boldsymbol{\%})$ \\
\hline \multicolumn{3}{c}{$\mathbf{3 0 3} \mathbf{~ K}$} \\
\hline Blank & 0.015 & 3.787 & - \\
0.2 & 0.012 & 3.030 & 20.0 \\
0.4 & 0.010 & 2.525 & 33.3 \\
0.6 & 0.005 & 1.262 & 66.7 \\
0.8 & 0.002 & 0.505 & 86.7 \\
1.0 & 0.001 & 0.253 & 93.3 \\
\hline
\end{tabular}




\begin{tabular}{|c|c|c|c|}
\hline Conc. (g/L) & $W_{\text {loss }}(\mathrm{g})$ & $C R \cdot 10^{-4}\left(\mathrm{~g} / \mathrm{hcm}^{2}\right)$ & $I E(\%)$ \\
\hline \multicolumn{4}{|c|}{$313 \mathrm{~K}$} \\
\hline Blank & 0.017 & 4.293 & - \\
\hline 0.2 & 0.014 & 3.534 & 17.0 \\
\hline 0.4 & 0.013 & 3.283 & 23.5 \\
\hline 0.6 & 0.006 & 1.515 & 64.7 \\
\hline 0.8 & 0.004 & 0.101 & 76.5 \\
\hline 1.0 & 0.002 & 0.505 & 88.2 \\
\hline \multicolumn{4}{|c|}{$323 \mathrm{~K}$} \\
\hline Blank & 0.021 & 5.303 & - \\
\hline 0.2 & 0.018 & 4.545 & 14.3 \\
\hline 0.4 & 0.016 & 4.040 & 23.8 \\
\hline 0.6 & 0.010 & 2.525 & 52.4 \\
\hline 0.8 & 0.005 & 1.263 & 76.2 \\
\hline 1.0 & 0.003 & 0.758 & 85.7 \\
\hline \multicolumn{4}{|c|}{$333 \mathrm{~K}$} \\
\hline Blank & 0.030 & 7.576 & - \\
\hline 0.2 & 0.027 & 6.818 & 10.0 \\
\hline 0.4 & 0.024 & 6.061 & 20.0 \\
\hline 0.6 & 0.014 & 3.536 & 53.3 \\
\hline 0.8 & 0.010 & 2.525 & 66.7 \\
\hline 1.0 & 0.006 & 1.515 & 80.0 \\
\hline
\end{tabular}

\subsection{Effect of Immersion Time}

Changes in weight loss, corrosion rate and inhibition efficiency recorded from the gravimetry studies carried out at room temperature, at various concentration of inhibitor and at time 24, 48, 72, 96 and $120 \mathrm{~h}$ are displayed in Figures 4, 5 and 6, respectively. Thw weight loss and corrosion rate were observed to increase with increasing immersion time and decrease with increasing inhibitor concentration. Whereas the inhibition efficiency was observed to follow a contrary path, it decreases with increasing immersion time and increases with increasing inhibitor concentration. Increase in inhibition efficiency with concentration may be ascribed to the increase in adsorption of the organic inhibitor on the Aluminium surface or at the solution interface [1]. The highest inhibition efficiency was recorded at $24 \mathrm{~h}$ of immersion, indicating that the adsorption of the organic inhibitor was completed within $24 \mathrm{~h}$. 


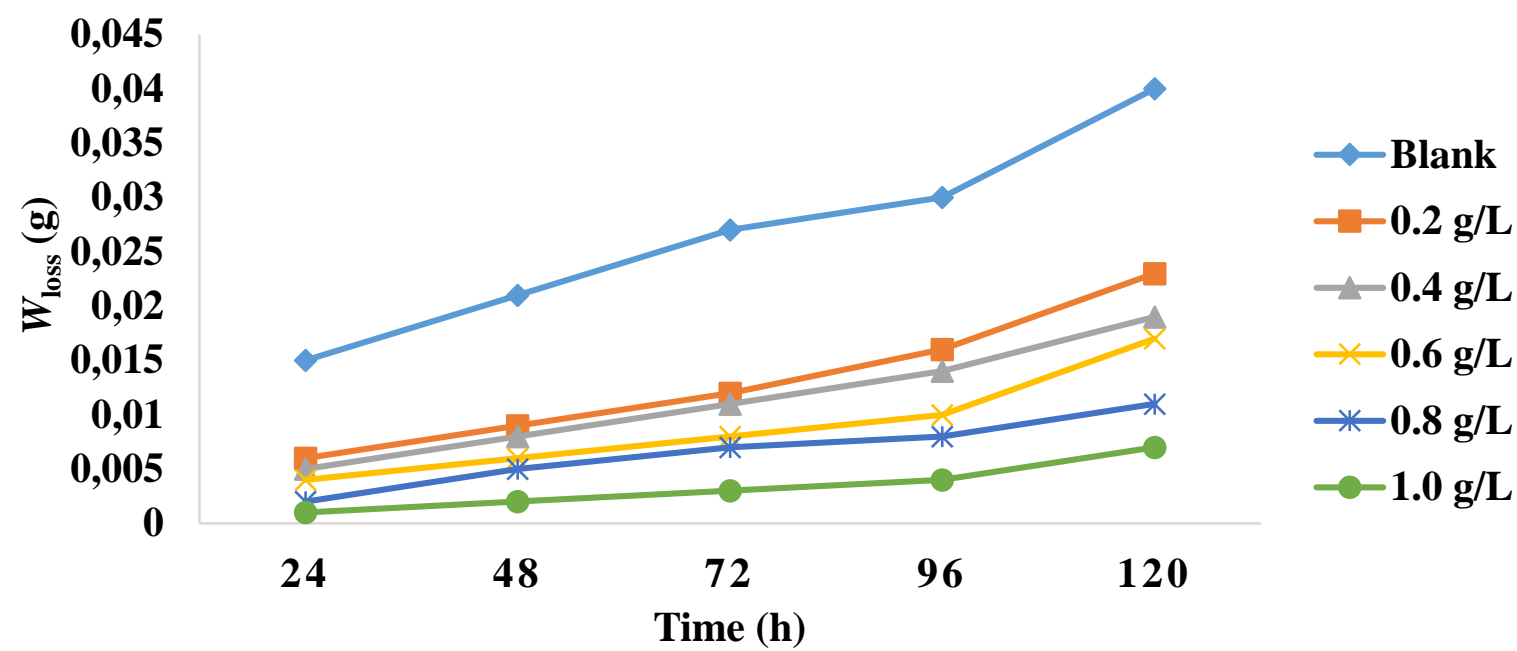

Figure 4. Effect of time on weight loss.

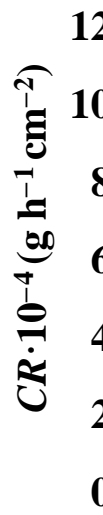

2
0
8
6
4
2
0

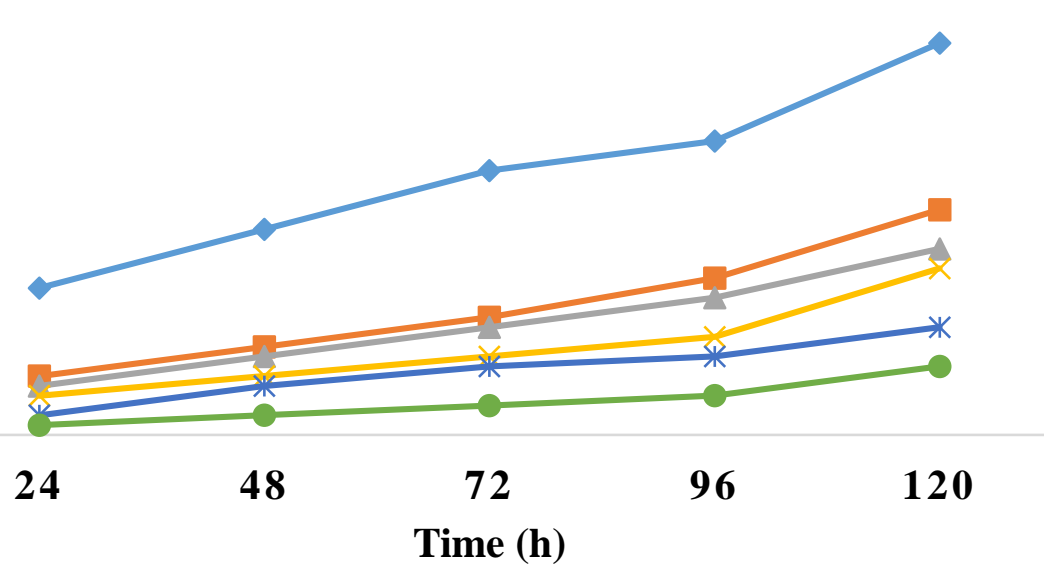

$\leadsto$ Blank

$-0.2 \mathrm{~g} / \mathrm{L}$

$+0.4 \mathrm{~g} / \mathrm{L}$

$\leftarrow 0.6 \mathrm{~g} / \mathrm{L}$

* $0.8 \mathrm{~g} / \mathrm{L}$

$1.0 \mathrm{~g} / \mathrm{L}$

Figure 5. Effect of time on corrosion rate.
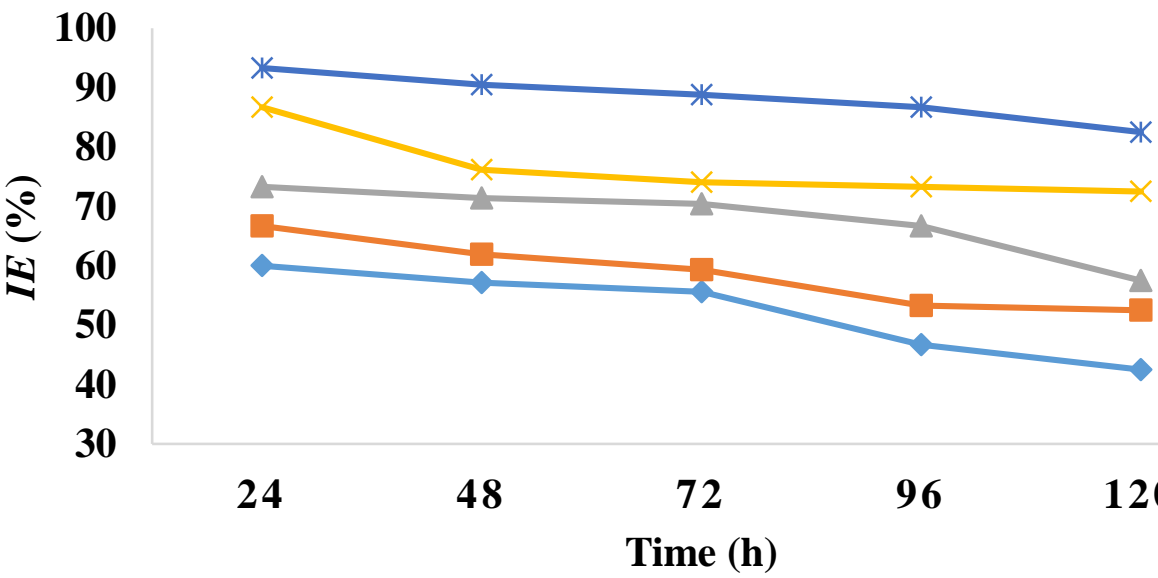

Figure 6. Effect of time on inhibition efficiency. 


\subsection{Kinetics and Thermodynamic studies}

Data of energy details of the reactions gives further proves of the corrosion protection mechanism of the inhibitor on the aluminium surface at various experimented temperatures [19]. In all reaction cases, corrosion rate increases as temperature increases. For the mechanism of corrosion reaction, the activation energy $E_{\mathrm{a}}$ was calculated using the Arrhenius energy model (Equation 9).

$$
\log C R=\log A-\frac{E_{\mathrm{a}}}{2.303 R T}
$$

Where $C_{\mathrm{R}}$ is the corrosion rate, $E_{\mathrm{a}}$ is the activation energy, $A$ is the Arrhenius constant, $R$ is the gas constant and $T$ is the temperature. From the corrosion rate measurements obtained at different inhibitor concentrations and temperatures (Table 1), a plot of $\log C_{\mathrm{R}}$ against $1 / T$ gives a linear plot (Figure 7), where $-E_{\mathrm{a}} / 2.303 R$ is the slope and the $\ln A$ equals the intercept at the vertical axis.

Applying the transition state equation, the enthalpy of activation $\Delta H$ and the entropy of activation $(\Delta S)$ were obtained for the corrosion rate of the Aluminium. The transition state equation is given as

$$
\log \frac{C R}{T}=\left(\log \frac{R}{N h}+\frac{\Delta S}{2.303 R}\right)-\frac{\Delta H}{2.303 R T}
$$

Where $\Delta H$ is the enthalpy of activation, $\Delta S$ is the entropy of activation, $h$ is the Planck constant and $N$ is the Avogadro number. The values $\Delta H$ and $\Delta S$ for the various concentrations of the inhibitor used were determined from the intercept and slope of the linear plot of $\log C R / T$ against $1 / T$ respectively (Table 2 ).

The values of the activation energy (Table 2) calculated was observed to be greater in the presence of the inhibitor, the $E_{\mathrm{a}}$ was determined to be $19.1 \mathrm{~kJ} \mathrm{~mol}^{-1}$ for $0.1 \mathrm{M} \mathrm{HCl}$ and was observed to increase with increasing concentration of the inhibitor. The highest value $60.43 \mathrm{~kJ} \mathrm{~mol}^{-1}$ was recorded at $0.8 \mathrm{~g} / \mathrm{L}$ of the inhibitor concentration. This result evident the fact that addition of inhibitor decreases the aluminium degradation, as a result of the formation of a stable metal complex layer in the acidic solution [20]. The $E_{\text {a }}$ values which are greater than $80 \mathrm{~kJ} \mathrm{~mol}^{-1}$ indicate a chemisorption, when the $E_{\mathrm{a}}$ values gave lesser values than $80 \mathrm{~kJ} \mathrm{~mol}^{-1}$ physisorption process occurred [1]. The experimental data for the $E_{\mathrm{a}}$ evidently showed that the adsorption of the inhibitor on the aluminium surface follows a physisorption mechanism.

The values of $\Delta H$ in Table 2 which are obtained for all the concentrations of the modified CNSL and the blank are positive indicating an endothermic reaction process. However, their negative values of $\Delta S$ indicates an increasing degree of disorderliness, showing a greater association of the inhibitor's molecules rather than dissociation [6-8]. 
Two kinetic models were applied; the pseudo-first order and pseudo-second order (Equations 11 and 12). The plot of $\ln \left(W_{0}-W_{\mathrm{f}}\right)$ against $t$ and the plot of $t / W_{\mathrm{f}}$ against $t$ for both models considered respectively, gave individual linear graphs. The $R^{2}$ values obtained from a pseudo-second order kinetic model was found to be the best fit in describing the kinetics of the adsorption of the inhibitors on the aluminium surface (Table 3 ).

$$
\begin{gathered}
\ln \left(W_{0}-W_{\mathrm{f}}\right)=\ln W_{0}-k t \\
\frac{t}{W_{\mathrm{f}}}=\frac{1}{W_{0}}+\left(\frac{1}{W_{\mathrm{f}}} t\right)
\end{gathered}
$$

Table 2. Thermodynamic parameters.

\begin{tabular}{cccc}
\hline Conc. $(\mathbf{g} / \mathbf{L})$ & $\boldsymbol{E}_{\mathbf{a}}\left(\mathbf{k J ~} \mathbf{~ m o l}^{\mathbf{- 1}}\right)$ & $\boldsymbol{\Delta H}\left(\mathbf{k J ~} \mathbf{~ m o l}^{\mathbf{- 1}}\right)$ & $\Delta \boldsymbol{S}\left(\mathbf{J ~ m o l}^{-\mathbf{1}}\right)$ \\
\hline Blank & 19.1 & 16.46 & -30.89 \\
$\mathbf{0 . 2}$ & 22.38 & 19.74 & -29.82 \\
$\mathbf{0 . 4}$ & 23.7 & 21.06 & -29.44 \\
$\mathbf{0 . 6}$ & 30.12 & 27.48 & -19.91 \\
$\mathbf{0 . 8}$ & 60.43 & 57.79 & -17.31 \\
$\mathbf{1 . 0}$ & 48.44 & 45.8 & -21.88 \\
\hline
\end{tabular}

Table 3. Pseudo first and second order kinetic models.

\begin{tabular}{ccccc}
\hline \multirow{2}{*}{ Conc. $(\mathbf{g} / \mathbf{L})$} & Pseudo-first order kinetics & \multicolumn{3}{c}{ Pseudo-second order kinetics } \\
\cline { 2 - 5 } & Equation & $\boldsymbol{R}^{\mathbf{2}}$ & Equation & $\boldsymbol{R}^{\mathbf{2}}$ \\
\hline Blank & $y=-0.0004 x-0.0119$ & 0.99 & $y=1.4952 x-2.2297$ & 0.99 \\
$\mathbf{0 . 2}$ & $y=-0.0002 x-0.0019$ & 0.97 & $y=1.3615 x+2.4401$ & 0.99 \\
$\mathbf{0 . 4}$ & $y=-0.0002 x-0.0009$ & 0.98 & $y=1.4456 x-4.7924$ & 0.99 \\
$\mathbf{0 . 6}$ & $y=-0.0002 x-0.0004$ & 0.87 & $y=1.3195 x+1.9797$ & 0.99 \\
$\mathbf{0 . 8}$ & $y=-0.0001 x-0.0006$ & 0.97 & $y=1.2814 x+2.4854$ & 0.99 \\
$\mathbf{1 . 0}$ & $y=-8 \mathrm{E}-05 x+0.0015$ & 0.86 & $y=1.4371 x-9.4854$ & 0.98 \\
\hline
\end{tabular}




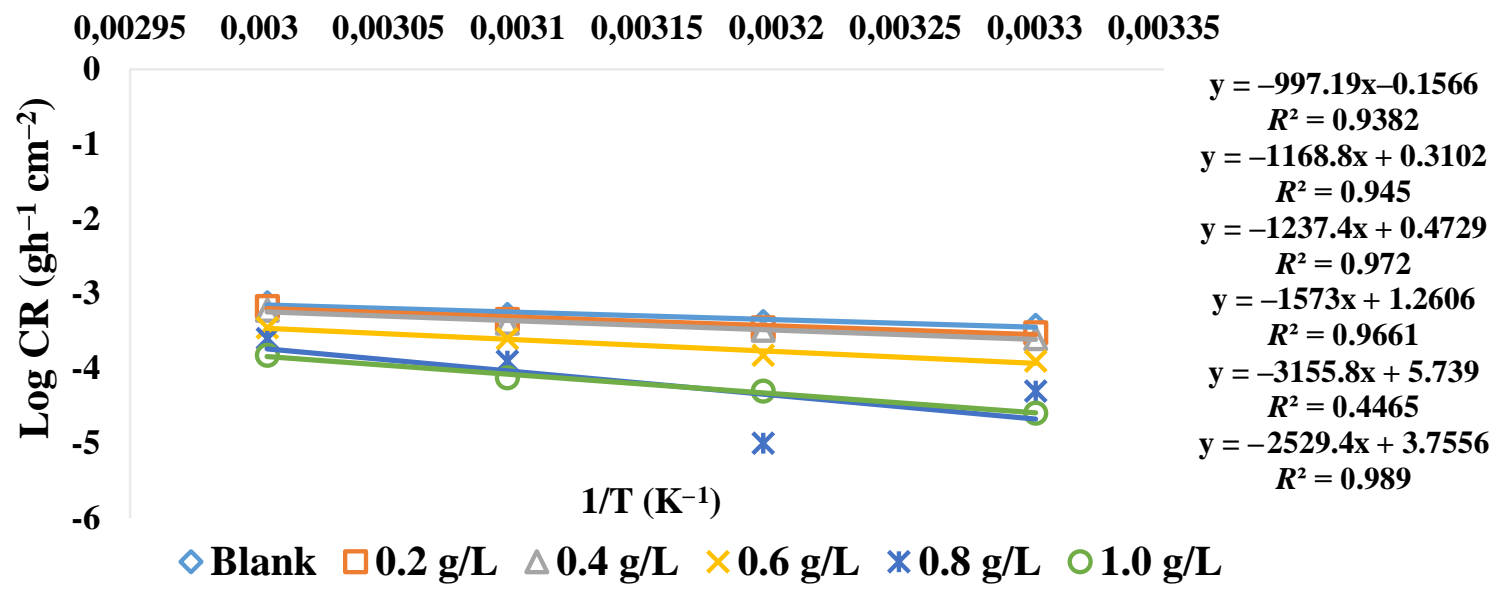

Figure 7. Arrhenius plot for determination of activation energy $\left(E_{\mathrm{a}}\right)$.

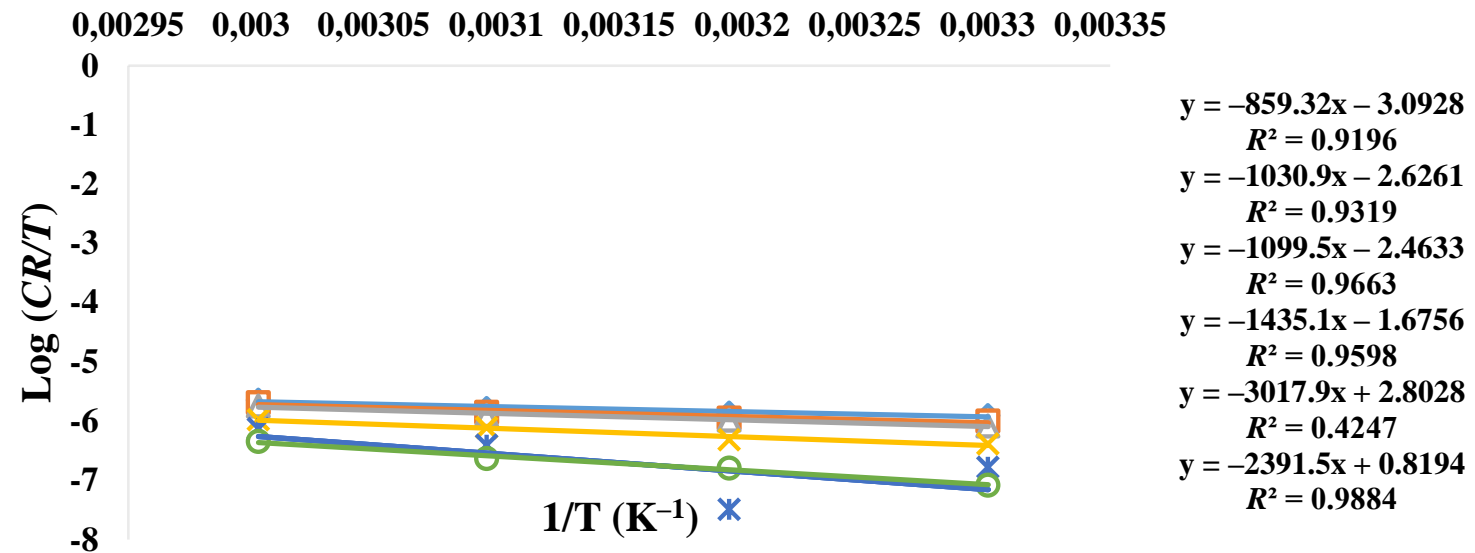

$\diamond$ Blank $\square 0.2 \mathrm{~g} / \mathrm{L} \triangle 0.4 \mathrm{~g} / \mathrm{L} \times 0.6 \mathrm{~g} / \mathrm{L} * 0.8 \mathrm{~g} / \mathrm{L} \bigcirc 1.0 \mathrm{~g} / \mathrm{L}$

Figure 8. Transition state plot for determination of $\Delta H$ and $\Delta S$.

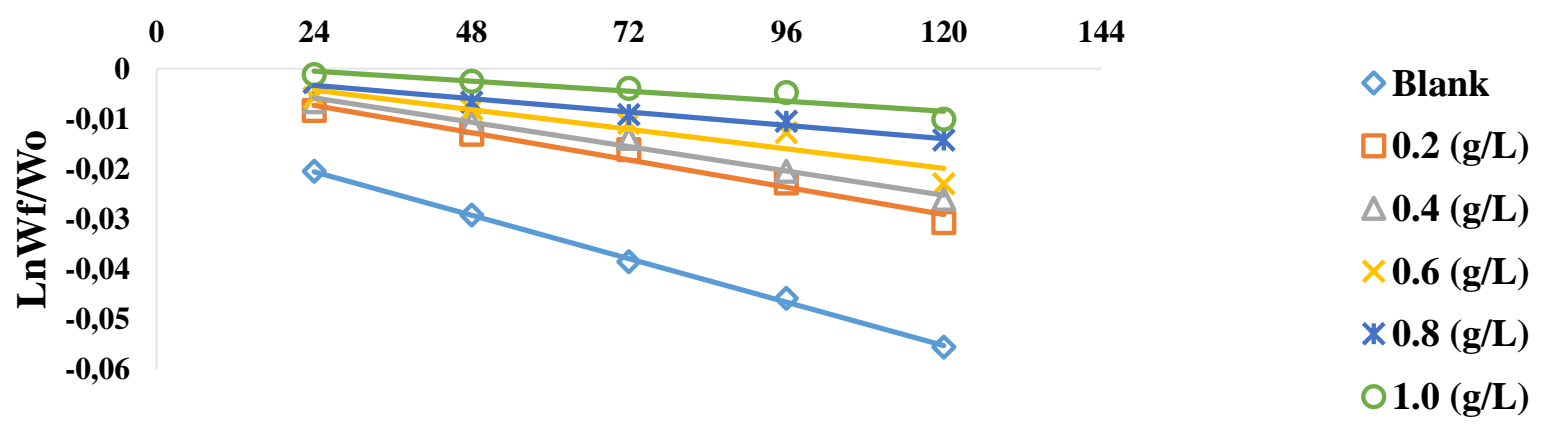

Time (h)

Figure 9. Pseudo-first order kinetic model plot. 


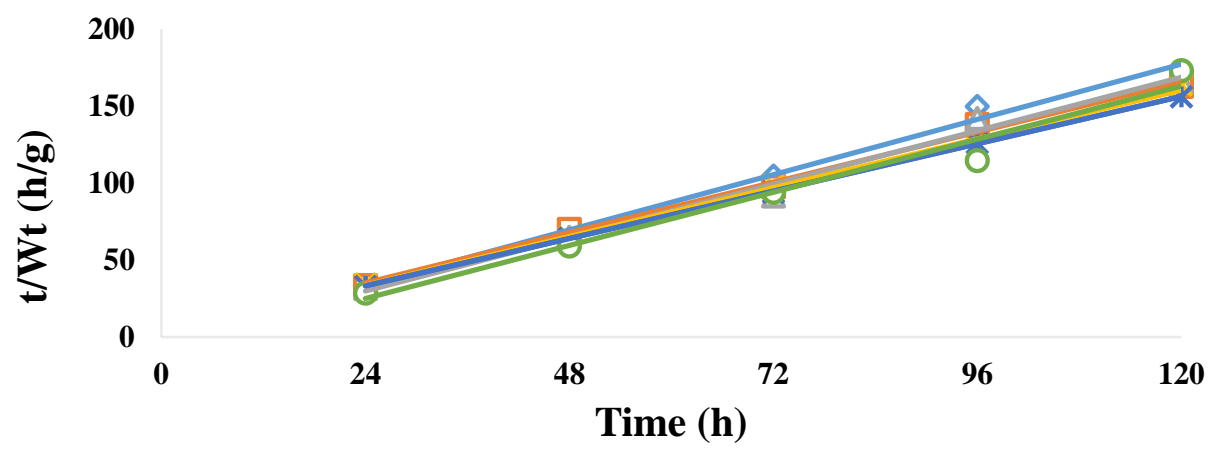

$\diamond$ Blank

$\square 0.2 \mathrm{~g} / \mathrm{L}$

$\triangle 0.4 \mathrm{~g} / \mathrm{L}$

$\times 0.6 \mathrm{~g} / \mathrm{L}$

$* 0.8 \mathrm{~g} / \mathrm{L}$

$\circ 1.0 \mathrm{~g} / \mathrm{L}$

Figure 10. Pseudo-second order kinetic model plot.

\subsection{Adsorption Isotherms}

Adsorption isotherm explains the mechanism of the interaction between the modified CNSL and the aluminium surface [21]. Varieties of adsorption isotherms were adopted include Langmuir, Temkin, Freundlich and El-Awady using equations (4), (5), (6) and (7), respectively. The linear regression coefficients $\left(R^{2}\right)$ obtained from each plot, the best fit of the isotherm model is determined. The Freundlich isotherm (Figure 13) had the best fit isotherm model for describing the interaction between the molecules of the modified CNSL and the aluminium surface. The Gibbs free energy $(\Delta G)$ was thus determined from the linear equation of the isotherm plot using the equation (12).

$$
\Delta G=-R T \ln \left(55.5 K_{\text {ads }}\right)
$$

Where $R$ is the gas constant, $T$ is temperature and $K_{\text {ads }}$ is the adsorption constants defined by the intercept of the linear plot of $\log \theta$ against $\log C$. The values $\Delta G$ in Table 4 were negative for all temperatures. These negative values of $\Delta G$ evidently explain the strong and stable interaction between the modified CNSL molecules and the aluminium surface and the process of adsorption is spontaneous. The negative values of $\Delta G$ increases with increasing temperature. Generally, the values of $\Delta G$ from $-40 \mathrm{~kJ} \mathrm{~mol}^{-1}$ and above indicate a charge transfer or sharing between the molecules of CNSL and the aluminium (Chemisorption). Whereas, values of $\Delta G$ ranging from $-20 \mathrm{~kJ} \mathrm{~mol}^{-1}$ downward show a physisorption mechanism [19]. Thus, $\Delta G$ values as presented in Table 4 show that the adsorption of the inhibitor is physisorption.

Table 4. Freundlich isotherm adsorption parameter.

\begin{tabular}{cccccc}
\hline Temperature (K) & Slope & Intercept & $\boldsymbol{R}^{\mathbf{2}}$ & $\boldsymbol{\Delta} \boldsymbol{G}\left(\mathbf{k J ~ m o l} \mathbf{~}^{-\mathbf{1}}\right)$ & $\boldsymbol{K}_{\text {ads }}$ \\
\hline $\mathbf{3 0 3}$ & 1.0326 & 0.0035 & 0.96 & -10.14 & 1.008 \\
$\mathbf{3 1 3}$ & 1.1274 & -0.0325 & 0.92 & -10.26 & 0.928 \\
$\mathbf{3 2 3}$ & 1.1968 & -0.0479 & 0.96 & -10.49 & 0.896 \\
$\mathbf{3 3 3}$ & 1.3756 & -0.0595 & 0.96 & -10.80 & 0.892 \\
\hline
\end{tabular}




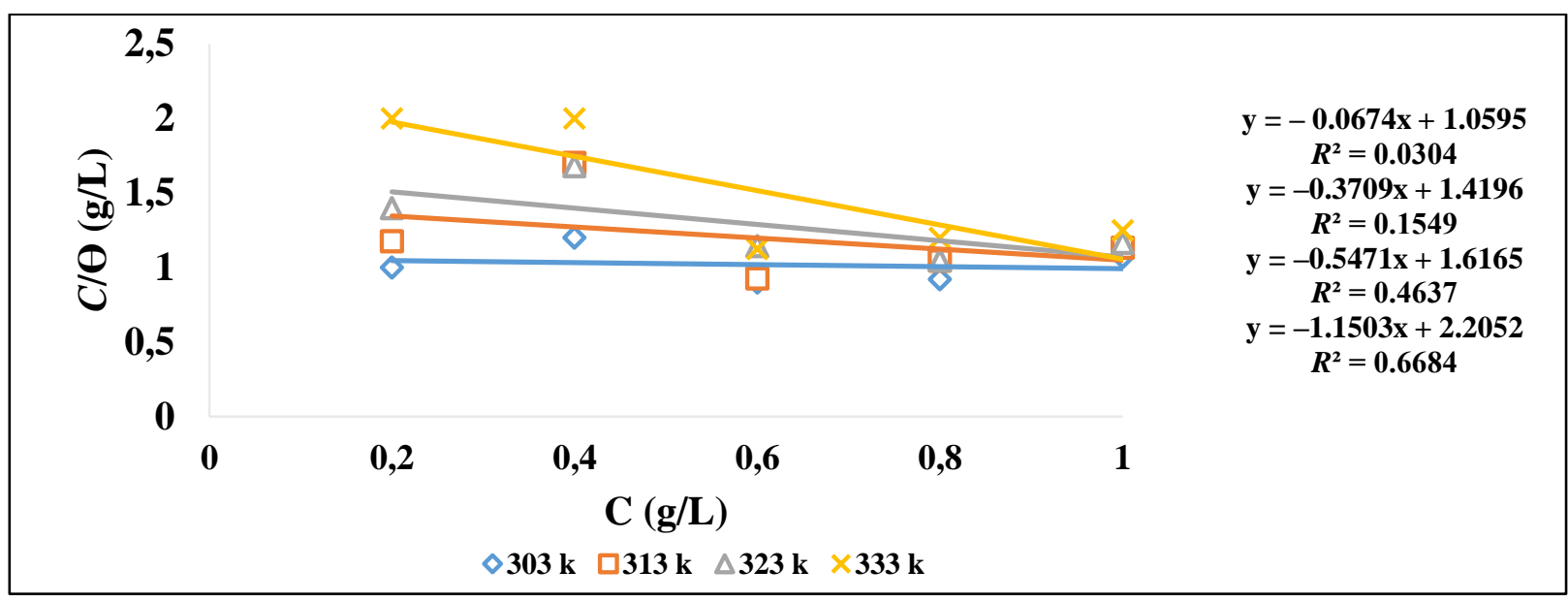

Figure 11. Langmuir isotherm plot.

$\mathrm{y}=0.4919 \mathrm{x}+0.9207$

$R^{2}=0.9352$

$\mathrm{y}=0.4763 \mathrm{x}+0.8503$

$R^{2}=0.8961$

$\mathrm{y}=0.4702 \mathrm{x}+0.8113$

$R^{2}=0.9095$

$\mathrm{y}=0.4544 \mathrm{x}+0.7563$

$R^{2}=0.9242$

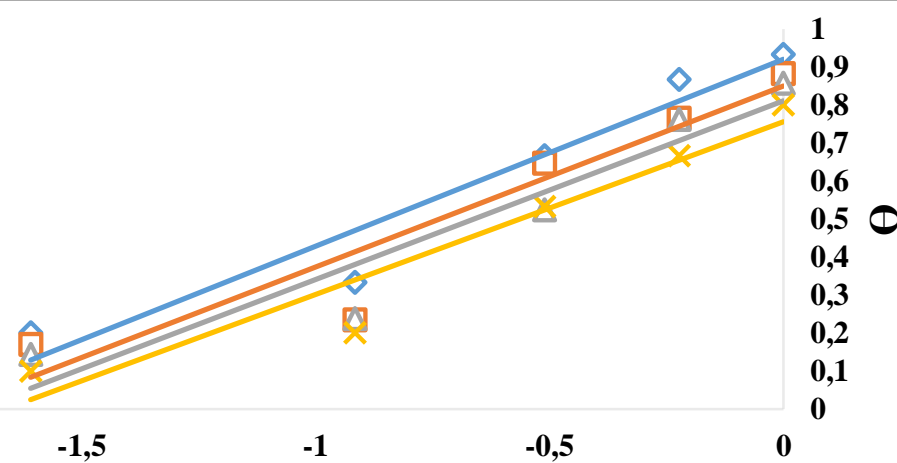

$-2$

$\operatorname{Ln} C(g / L)$

$\diamond 303 \mathrm{k} \square 313 \mathrm{k} \triangle 323 \mathrm{k} \times 333 \mathrm{k}$

Figure 12. Temkin isotherm plot.

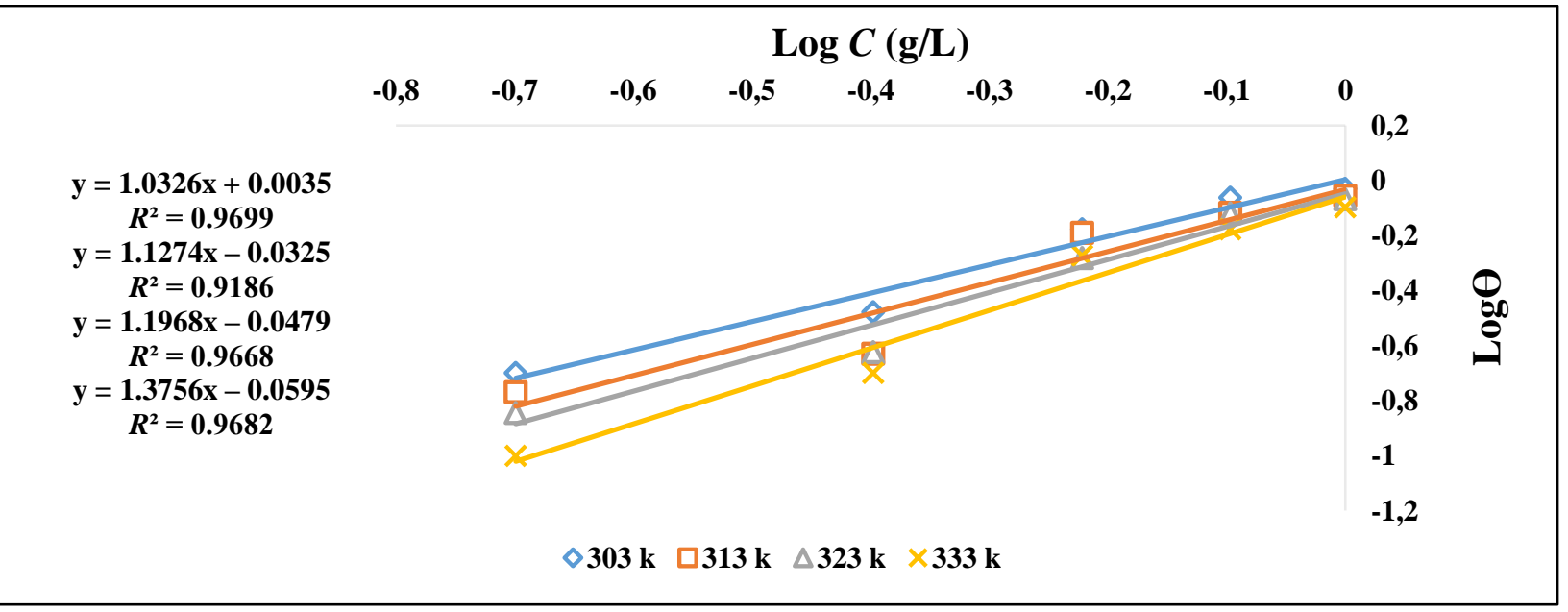

Figure 13. Freundlich isotherm plot. 


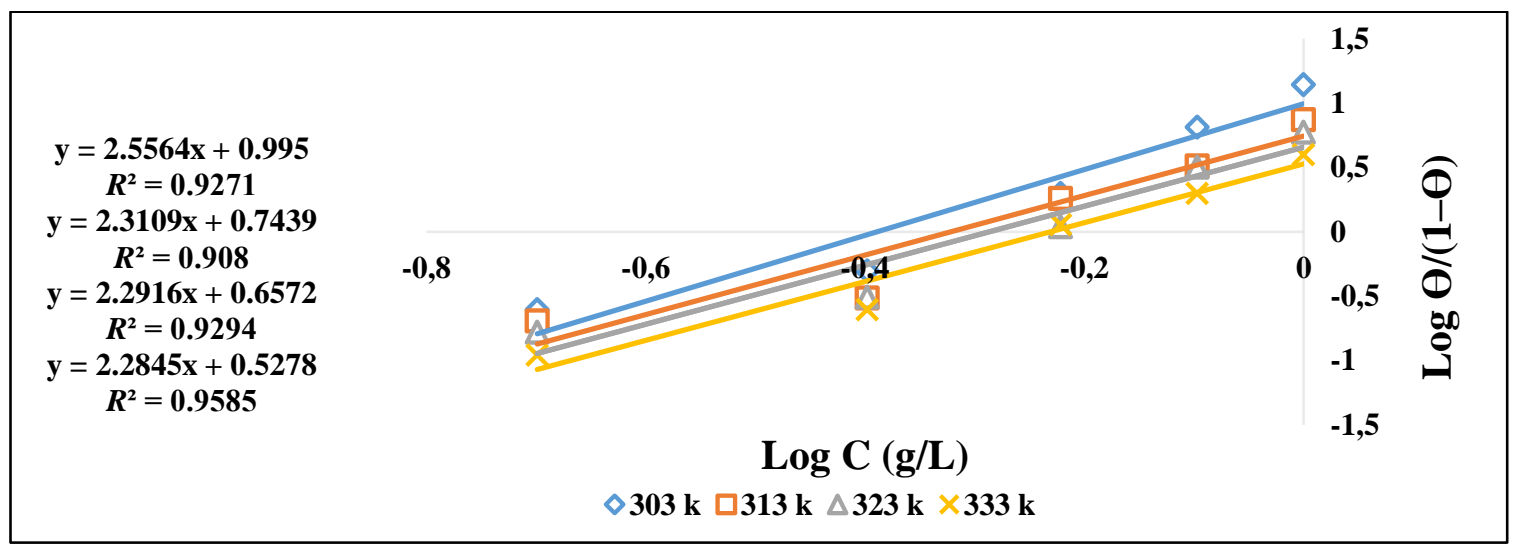

Figure 14. El-Awady isotherm plot.

\subsection{FTIR Analysis}

The synthesis of the synthesized inhibitor was confirmed using FTIR analysis carried out on both the extracted CNSL and the synthesized derivative (Figures 15 and 16).

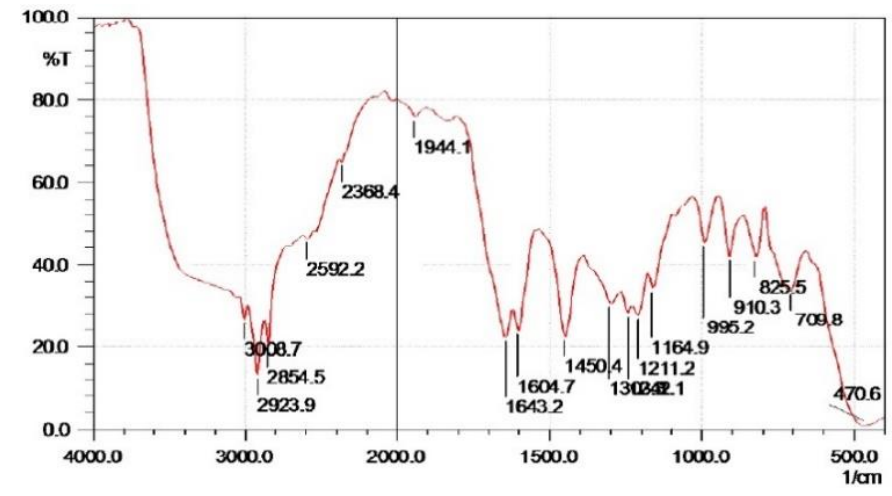

Figure 15. FTIR spectrum of extracted CNSL.

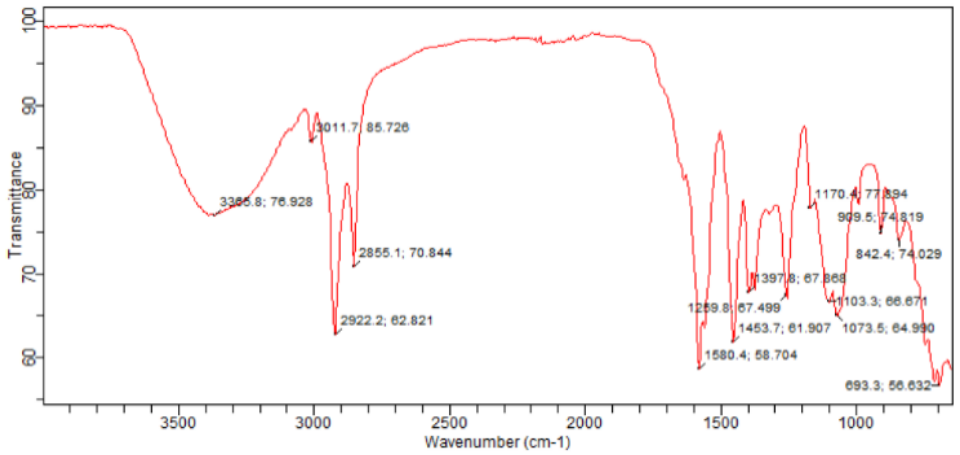

Figure 16. FTIR of synthesized CNSL-triethanolamine derivative.

\section{Conclusion}

The synthesized CNSL-triethanolamine derivative exhibits an aluminium corrosion inhibition property in $0.1 \mathrm{M} \mathrm{HCl}$ solution. Gravimetry analysis carried out showed that the inhibition efficiency increases as the inhibitor concentration increases and decreased with 
increasing temperature and immersion time. The inhibition efficacy was studied at various inhibitor concentrations of $0.2,0.4,0.6,0.8$ and $1.0 \mathrm{~g} / \mathrm{L}$, temperatures of 303, 313, 323, $333 \mathrm{~K}$ and at time intervals of $24,48,72,96$ and $120 \mathrm{~h}$ respectively. The kinetic studies showed that pseudo-second order kinetic model best describes the kinetic and from the thermodynamic and adsorption isotherm studies and Freundlich isotherm model best describes the adsorption of the inhibitor to the aluminium surface, the adsorption was observed to be physisorption and the process was recorded to be spontaneous and endothermic. The corrosion process was also observed to be endothermic.

\section{Reference}

1. G.A. Ijuo, H.F. Chahul and I.S. Eneji, Kinetic and thermodynamic studies of corrosion inhibition of mild steel using Bridelia ferruginea extract in acidic environment, $J$. $A d v$. Electrochem., 2016, 2,107-112.

2. A. Singh, E.E. Ebenso and M.A. Quraishi, Corrosion inhibition of carbon steel in $\mathrm{HCl}$ solution by some plant extracts, Int. J. Corros., 2012, 2012, 1-20. doi: $\underline{10.1155 / 2012 / 897430}$

3. N.O. Eddy, S.A. Odoemelam and I.N. Ama, Ethanol extract of Ocimum gratissimum as a green corrosion inhabitor for the corrosion of mild steel in $\mathrm{H}_{2} \mathrm{SO}_{4}$, Green Chem. Lett. Rev., 2010, 3,165-172. doi: 10.1080/17518251003636428

4. S.C. Joycee, A.S. Raja, A.S. Amalraj and S. Rajendran, Inhibition of corrosion of mild steel pipeline carrying simulated oil well water by Allium sativum (garlic) extract, Int. J. Corros. Scale Inhib., 2021, 10, 943-960. doi: 10.17675/2305-6894-2021-10-3-8

5. O.M. Fayomi, H.F. Chahul, D.C. Ike, G.I. Ndukwe and I.M. Phoebe, Thermodynamic and Adsorption Study of the Corrosion Inhibition of Mild Steel by Aframomum chrysanthum Extract in 0.1 M Hydrochloric Acid Solution, Asian J. Appl. Chem. Res., 2021, 8, 64-73. doi: $10.9734 / \mathrm{ajacr} / 2021 / \mathrm{v} 8 \mathrm{i} 430200$

6. F.E. Abeng, V.D. Idim, and P.J. Nna, Kinetics and thermodynamic studies of corrosion inhibition of mild steel using methanolic extract of Erigeron floribundus (Kunth) in $2 \mathrm{M}$ HCl solution, World News Nat. Sci., 2017, 10, 26-38.

7. N.O. Eddy and E.E. Ebenso, Corrosion inhibition and adsorption properties of ethanol extract of Gongronema latifoliumon mild steel in $\mathrm{H}_{2} \mathrm{SO}_{4}$, Pigm. Resin. Tech., 2010, 39, 77-83. doi: 10.1108/03699421011028653

8. N.O. Eddy, and P.A. Mamza, Inhibitive and adsorption properties of ethanol extract of seeds and leaves of Azadirachta indica on the corrosion of mild steel in $\mathrm{H}_{2} \mathrm{SO}_{4}$, Port. Electrochim. Acta, 2009, 27,443-456. doi: 10.4152/pea.200904443

9. W.A.W. Elyn-Amira, A.A. Rahim, H. Osman, K. Awang and P.B. Raja, Corrosion inhibition of mild steel in I M HCl solution by Xylopia ferruginea leave from different extract and partition, Int. J. Electrochem. SCR, 2011, 6, 2998-3016.

10. S.H. Senger, A.G. Mohod and Y.P. Kandectod, Perfomance Evaluation of Kiln for cashew nut shell carbonization and liquid, Int. J. Energy Eng., 2012, 2, 78-85. doi: 10.5923/j.ijee.20120203.04 
11. C.O. Victor-Oji, U.J. Chukwu and O. Akaranta, Comparative Study of Cashew Nut Shell Liquid and a CommerCRal Demulsifier for Treating Crude Oil Emulsions, Chem. Sci. Int. J., 2019, 28, 1-17. doi:10.9734/CSJI/2019/v28i430148

12. A.M. Atta, H.A. Al-Lohedan, M.M. Abdullah and S.M. ElSaeed, Application of new amphiphilic ionic liquid based on ethoxylated octadecylammonium tosylate as demulsifier and petroleum crude oil spill dispersant, J. Ind. Eng. Chem., 2016, 33, 122 130. doi: $10.1016 /$ j.jiec.2015.09.028

13. K.I. Suresh and V.S. Kishanprasad, Synthesis, structure, and properties of novel polyols from cardanol and developed polyurethanes, Ind. Eng. Chem. Res., 2005, 44, 45044512. doi: $10.1021 / \mathrm{ie} 0488750$

14. M.G. Tsoeunyane, M.E. Makhatha and O.A. Arotiba, Corrosion inhibition of mild steel by poly (butylene succinate)-L-histidine extended with 1, 6-diisocynatohexane polymer composite in $1 \mathrm{M} \mathrm{HCl}$, Int. J. Corros., 2019, 2019, 1-12. doi: $10.1155 / 2019 / 7406409$

15. O. Dagdag, Z. Safi, R. Hsossou, H. Erramli, M. El Bouchti, N. Wazzan, L. Guo, C. Verma, E.E. Ebenso and A. El Harfi, Epoxy pre-polymers as new and effective materials for corrosion inhibition of carbon steel in acidic medium; computational and experimental studies, Sci. Rep., 2019, 9, 1-14. doi: 10.1038/s41598-019-48284-0

16. K.K. Alaneme and S.J. Olusegun, Corrosion inhibition performance of lignin extract of sunflower (Tithonia diversifolia) on medium carbon low alloy steel immersed in $\mathrm{HCl}$ solution, Leonardo J. Sci., 2012, 20, 59-70.

17. E.E. Ebenso, H. Alamu, S.A. Umoren and L.B. Obor, Inhibition of mild steel corrosion in sulphuric acid using alizarin yellow dye and synergistic iodide additive, Int. J. Electrochem. Sci., 2008, 3, 1325-1339.

18. M.M. Ihebrodike, A.U. Anthony, B.O. Kelechukwu and G.A. Alozie, The inhibition effect of Solanummelongena L. leaf extract on the corrosion of Aluminium in tetraoxosulphate (vi) acid, Afri. J. Pure Appl. Chem. 2010, 4, 158-165.

19. D.K. Verma and F. Kham, Corrosion inhibition of mild steel by extract of Bryophyllum pinnatum leaves in acidic solution, Chem. Mater. Res., 2015, 7, 69-76.

20. A. Ostovari, S.M. Hoseinieh, M. Peikari, S.R. Shadizadeh and S.J. Hashemi, Corrosion inhibition of mild steel in $1 \mathrm{M} \mathrm{HCl}$ solution by henna extract: A comparative study of the inhibition by henna and its constituents (Lawsone, Gallic acid, a-D-Glucose and Tannic acid), Corros. Sci., 2009, 51, 1935-1949. doi: 10.1016/j.corsci.2009.05.024

21. I.B. Obot, E.E. Ebenso and M.M. Kabanda, Metronidazole as environmentally safe corrosion inhibitor for mild steel in $0.5 \mathrm{M} \mathrm{HCl}$ : Experimental and Theoretical investigation, J. Env. Chem. Eng., 2013, 1, 431-439. doi: 10.1016/j.jece.2013.06.007 